\title{
physiokongress
}

24.-26. Januar 2014

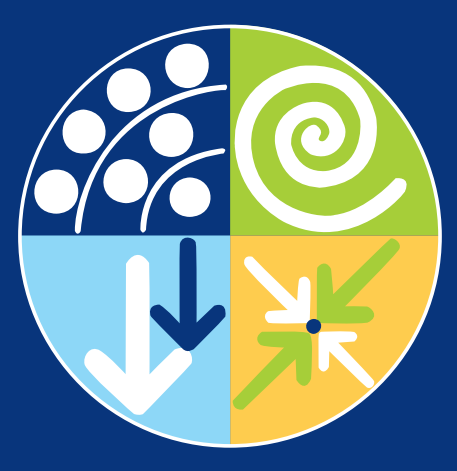

\section{Grenzgänger willkommen}

\section{PHYSIOKONGRESS 2014: DER SONNTAG Bunt gemischt}

ist das Programm auf dem Therapieforum zum physiokongress

im Herzen der Ausstellung. Sonntag ist ergotag, bei dem

neurologisch interessierte Therapeuten fündig werden.

Physios sind herzlich eingeladen.

\section{Therapieforum}

\subsection{Uhr bis $16 \mathrm{Uhr}$}

$>$ Anatomy Trains und Myofasziales Taping (M. Erhard)

$>$ Informationen zu einem Fernhochschul-Studiengang (T. Haas)

$>$ Schluss mit Regressen und Rechnungskürzungen (R. Buchner)

$>$ Microkinesitherapie (W. Kayser)

$>$ Physiotherapie und orthomolekulare Medizin (S. von Dobschütz)

$>$ Slackline in der Therapie (M. Bartke)

$>$ Training bei unspezifischen Nackenschmerzen (K. Steffens)

$>$ Wie wirkt Hippotherapie? (S. Lamprecht)

$>$ Treffpunkt Bewegung (G. Pidt)

$>$ Wie verdiene ich mit Gerätetraining Geld? (G. Pidt)
THERAPRO 2014

\section{Infos und Anmeldung}

Thiemes physiokongress findet im Rahmen der Messe TheraPro statt, der größten Messe für Therapieberufe in Süddeutschland. Hier können Sie sich über Aktuelles aus der Branche und neue Produkte informieren. Zwischen den Vorträgen ist genügend Zeit, um sich in Ruhe umzusehen.

Mehr zum Programm des physiokongresses finden Sie unter www.thieme.de/physiokongress. Über die TheraPro können Sie sich informieren unter www.therapro-messe.de. physiopraxis-Abonnenten und Besucher des physiokongresses 2013 erhalten einen ermäßigten Eintrittspreis! 